\title{
Two XMAP215/TOG Microtubule Polymerases, Alp14 and Dis1, Play Non-Exchangeable, Distinct Roles in Microtubule Organisation in Fission Yeast
}

\author{
Masashi Yukawa ${ }^{1,2}$, Tomoki Kawakami ${ }^{1}$, Corinne Pinder ${ }^{1,2,3}$ and Takashi Toda ${ }^{1,2, *(D)}$ \\ 1 Division of Biological and Life Sciences, Graduate School of Integrated Sciences for Life, \\ Hiroshima University, 1-3-1 Kagamiyama, Higashi-Hiroshima, Hiroshima 739-8530, Japan; \\ myukawa@hiroshima-u.ac.jp (M.Y.); m176779@outlook.com (T.K.); corinnepinder@outlook.com (C.P.) \\ 2 Hiroshima Research Center for Healthy Aging (HiHA), Hiroshima University, 1-3-1 Kagamiyama, \\ Higashi-Hiroshima, Hiroshima 739-8530, Japan \\ 3 The Francis Crick Institute, 1 Midland Road, London NW1 1AT, UK \\ * Correspondence: takashi-toda@hiroshima-u.ac.jp; Tel.: +81-82-424-7868
}

Received: 4 October 2019; Accepted: 12 October 2019; Published: 15 October 2019

\begin{abstract}
Proper bipolar spindle assembly underlies accurate chromosome segregation. A cohort of microtubule-associated proteins orchestrates spindle microtubule formation in a spatiotemporally coordinated manner. Among them, the conserved XMAP215/TOG family of microtubule polymerase plays a central role in spindle assembly. In fission yeast, two XMAP215/TOG members, Alp14 and Dis1, share essential roles in cell viability; however how these two proteins functionally collaborate remains undetermined. Here we show the functional interplay and specification of Alp14 and Dis1. Creation of new mutant alleles of alp14, which display temperature sensitivity in the absence of Dis1, enabled us to conduct detailed analyses of a double mutant. We have found that simultaneous inactivation of Alp14 and Dis1 results in early mitotic arrest with very short, fragile spindles. Intriguingly, these cells often undergo spindle collapse, leading to a lethal "cut" phenotype. By implementing an artificial targeting system, we have shown that Alp14 and Dis1 are not functionally exchangeable and as such are not merely redundant paralogues. Interestingly, while Alp14 promotes microtubule nucleation, Dis1 does not. Our results uncover that the intrinsic specification, not the spatial regulation, between Alp14 and Dis1 underlies the collaborative actions of these two XMAP215/TOG members in mitotic progression, spindle integrity and genome stability.
\end{abstract}

Keywords: fission yeast; microtubule polymerase; XMAP215/TOG; mitotic spindle; spindle pole body; kinetochore

\section{Introduction}

Microtubules (MTs) play diverse roles in a wide range of biological processes including cell cycle progression, development and differentiation pathways [1]. During mitosis, spindle MTs assemble to form a bipolar structure that emanates from the two spindle poles. The bipolar spindle functions as the division apparatus for sister chromatids, generating pulling forces to move them towards opposite poles to ensure equal partition of genetic material. Errors in this process can lead to cell death and/or aneuploidy, a major risk factor for miscarriage, birth defects and tumourigenesis [2,3].

MTs are intrinsically dynamic, a characteristic termed dynamic instability [4,5]. In a living cell, a cohort of proteins, collectively known as microtubule-associated proteins (MAPs), participate in spindle assembly, stability and maintenance as structural and/or regulatory factors. A conserved family of MAPs, here referred to as the XMAP215/TOG (Tumour Overexpressed Gene) family, is deeply rooted in the eukaryotic branch of the tree of life and arguably the most important regulator in 
MT organisation [6-9]. Originally discovered as a factor conferring the dynamic properties of MTs in Xenopus egg extracts [10], homologues have been identified in virtually all eukaryotic species [9]. The seminal advancement of our understanding of the XMAP215/TOG family was the discovery that XMAP215 is a MT polymerase [11]; this protein is capable of incorporating $\alpha / \beta$-tubulin heterodimers at the plus end of pre-existing MTs. Since then, this activity has been proven for other members of the family from a diverse range of organisms [8]. Consistent with this notion, depletion or mutational inactivation of XMAP215/TOG family members generally results in the emergence of shorter, unstable MTs in various cell types [8].

Members of the XMAP215/TOG family have similar domain organisation. The N-terminal region contains multiple (two to five) TOG domains that bind and trap free $\alpha / \beta$-tubulin heterodimers $[12,13]$, followed by the MT lattice-binding domain and finally the $\mathrm{C}$-terminal region responsible for interaction with various binding partners [8]. Fission yeast is unique in that its genome contains two XMAP215/TOG paralogues, alp14/mtc1 and dis1 [14,15], unlike other organisms that normally encode only one gene [9]. This provides an opportunity in which to study the conservation and diversification of the XMAP215/TOG family members within the same organism. It has been shown that both Alp14 and Dis1 behave biochemically as canonical MT polymerases [16,17]. Genetically, alp14 and dis1 share essential functions for cell viability; while each single deletion is viable, strains containing double gene deletions are inviable [18]. These phenomena imply that Alp14 and Dis1 are redundant paralogues. However, several lines of data are not consistent with this simple scenario. For instance, Alp14 and Dis1 form a complex with different MAP partners in a cell; Alp14 binds Alp7/TACC (Transforming Acidic Coiled-Coil), while Dis1 interacts with Mal3/EB1 [16,19]. In addition, during mitosis, the cellular localisation of Alp14 and Dis1 is different; Alp14 is first recruited to the spindle pole body (SPB, the fungal equivalent of the centrosome), while Dis1 is localised to the kinetochore [15,20-23].

Interestingly, it has been shown that Alp14 is capable of promoting the very initial step of MT assembly at the SPB, namely MT nucleation by binding to the universal MT nucleator $\gamma$-tubulin complex $(\gamma-\mathrm{TuC})$ [24], which is also the case for XMAP215 [25]. Whether or not Dis1 could also promote MT nucleation remains to be determined. By contrast, we and others have recently shown that Dis1 is capable of promoting MT depolymerisation, rather than polymerisation, under some physiological circumstances [26,27].

In this study, we have addressed the reason for synthetic lethality between alp14 and dis1 by creating and characterising new alp14 mutant alleles that display temperature sensitivity in the absence of Dis1. Our analyses show that Alp14 and Dis1 collaborate in assembly and maintenance of bipolar spindle MTs as MT polymerases. Intriguingly, we have found that Alp14 and Dis1 are not redundant paralogues, but instead these MAPs play intrinsically diversified roles in spindle MT assembly in a spatially distinct manner.

\section{Results}

\subsection{Creation of Temperature-Sensitive alp14 Mutants in the Absence of Dis1}

To explore the physiological and phenotypic consequences resulting from simultaneous inactivation of two XMAP215/TOG paralogues in fission yeast, we sought to isolate temperaturesensitive (ts) mutants of alp14 in the dis1 deletion (dis1 $\Delta$ ) background. For this purpose, a pool of alp14-GFP-kanR fragments amplified with error-prone PCR [28] was introduced into a dis1 $\Delta$ strain and G418-resistant colonies were first selected at $27^{\circ} \mathrm{C}$. These colonies were replica-plated and incubated at $36{ }^{\circ} \mathrm{C}$. From this screen, we isolated 6 ts candidates (Materials and Methods). These ts isolates were then backcrossed with a wild-type strain and random spore analysis was performed to check whether temperature-sensitivity cosegregated with G418 resistance (alp14-GFP-kanR) and Hygromycin B resistance (dis1::hphR). Spot tests were performed to assess the ts phenotype of individual mutants (Figure 1A). After confirming these characteristics, the nucleotide sequence of the alp14 gene in individual mutants was determined. Each mutant contained between one and five point mutations 
and mutation sites were spread across the entirety of Alp14. This includes the N-terminal TOG repeats, the C-terminal MT-binding region and the last 100 amino acid sequence that is required for binding to Alp7/TACC [19] (Figure 1B). We chose alp14-26 for subsequent analyses as this mutant allele displayed strong temperature sensitivity in the dis $1 \Delta$ background (no growth at temperatures above $34^{\circ} \mathrm{C}$ ) and contained only a single point mutation (C450R) (Figure 1A,B, respectively).

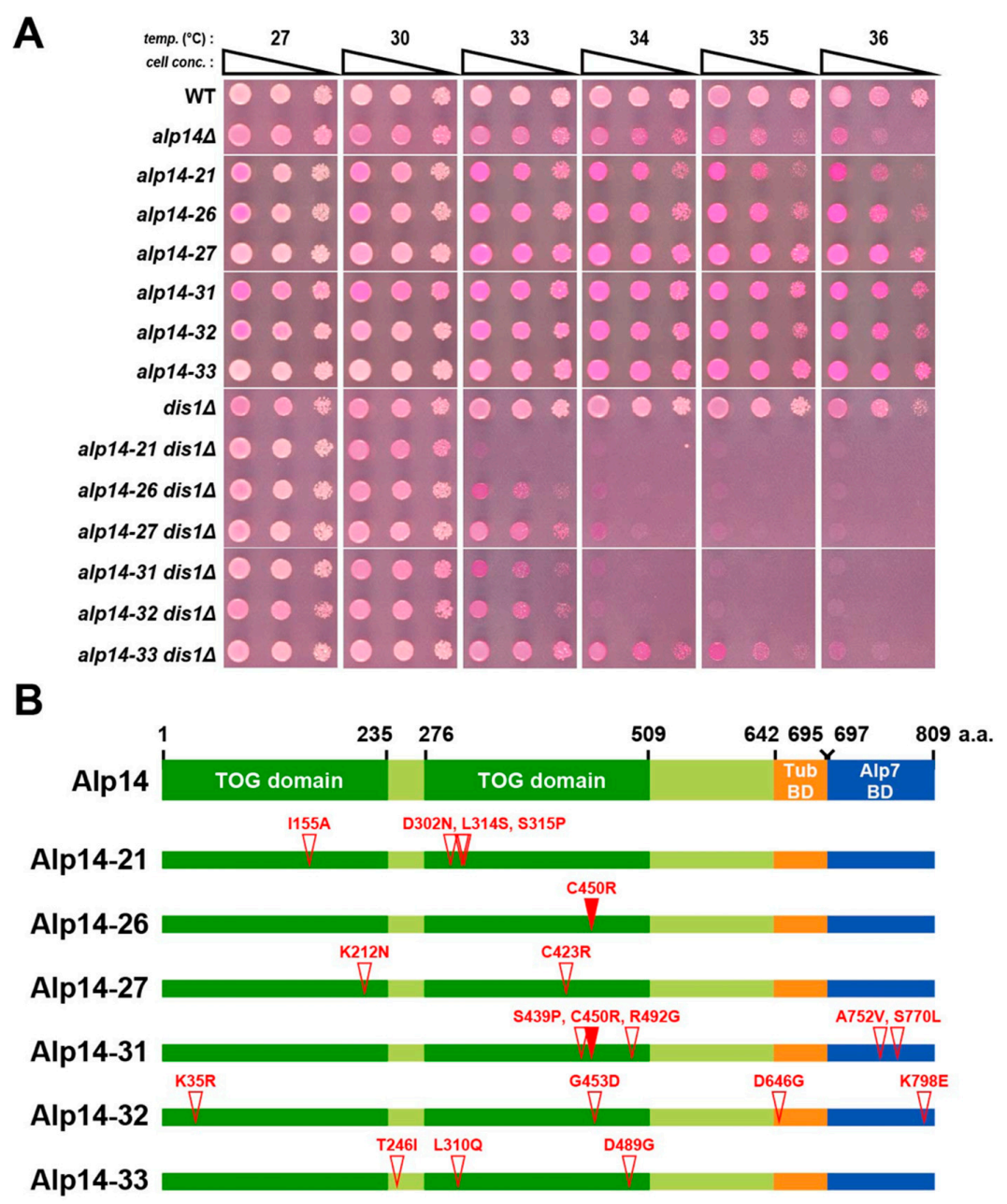

Figure 1. Isolation of alp14 temperature-sensitive mutations in the dis1 $\Delta$ background. (A) Spot test. Indicated strains were serially (10-fold) diluted, spotted onto rich YE5S plates containing Phloxine B and incubated at the indicated temperatures for 2-3 d. (B) Mutation sites in the alp14 mutants. Mutated amino acid residues are shown with open triangles. Note that the C450R mutation was found in both alp14-26 and alp14-31 (shown with closed triangles).

\subsection{Alp14 and Dis1 Collaborate to Regulate Proper Mitotic Progression and Promote Spindle Elongation}

As the first step towards characterising the functional interplay between Alp14 and Dis1, we assessed the mitotic behaviour of alp14-26dis1 $\Delta$ mutant cells incubated at $36{ }^{\circ} \mathrm{C}$ for $2 \mathrm{~h}$ and compared them with those of individual single mutants, alp $14 \Delta$ and wild-type cells. In either dis $1 \Delta$ or alp14-26 single mutant cells the mitotic index, judged by the presence of spindle MT structures (mCherry-Atb2) [29], was increased compared to wild-type cells (23\% and 38\% respectively vs $15 \%$ in wild-type cells, Figure 2A). In the alp $14 \Delta$ strain, the mitotic index was higher (47\%), indicating that alp14-26 is hypomorphic and may retain some residual activity. Interestingly, alp14-26dis1 $\Delta$ cells exhibited a mitotic index of $60 \%$, higher than that in alp14 $\Delta$, indicating that Alp14 and Dis1 regulate mitotic progression in an independent yet additive fashion (Figure 2A). 
Mitosis in fission yeast is divided into three distinct phases based upon spindle behaviour [30]. Phase 1 (corresponding to prophase and prometaphase) constitutes the period in which spindles start to assemble and elongate until a fixed length of $\sim 2.5 \mu \mathrm{m}$; in phase 2 (corresponding to metaphase and anaphase A) the spindle is maintained at a constant length of $\sim 2.5 \mu \mathrm{m}$; phase 3 (corresponding to anaphase B) involves final spindle elongation from $\sim 2.5$ to $\sim 10 \mu \mathrm{m}$. We measured spindle length in each strain and found that although dis $1 \Delta$ cells did not display a significant difference from wild-type cells $(3.4 \mu \mathrm{m}$ vs $3.8 \mu \mathrm{m}$, respectively), alp14-26 cells showed a reduction $(2.3 \mu \mathrm{m})$, yet were longer than alp $14 \Delta$ cells $(1.5 \mu \mathrm{m})$. Consistent with the additive impact of these two MAPs on mitotic index, alp14-26dis1 $\Delta$ cells showed the shortest length $(0.7 \mu \mathrm{m})$ (Figure 2B), suggesting that mutant cells stay in this stage for a longer period of time. Thus, Alp14 in collaboration with Dis1 plays an important role in proper spindle length control.
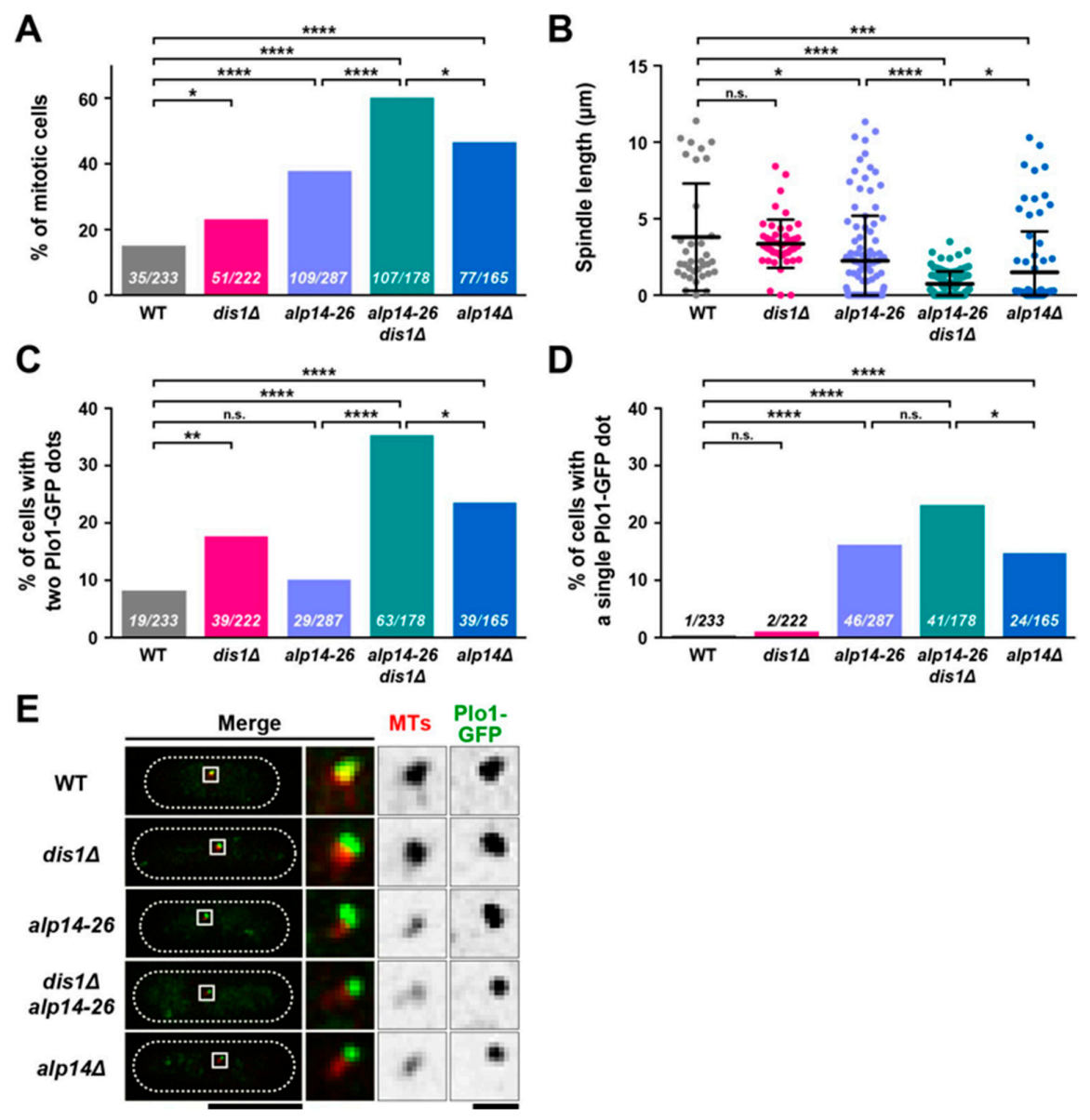

Figure 2. Alp14 and Dis1 collaborate to regulate proper mitotic progression. Exponentially growing cells at $27^{\circ} \mathrm{C}$ were shifted to $36^{\circ} \mathrm{C}$ for $2 \mathrm{~h}$. Spindle MTs (mCherry-Atb2, red) and mitotic SPBs (Plo1-GFP, green) were visualised. (A) Mitotic indices. Mitotic cells were identified as those containing mitotic spindles or those without interphase MTs. $p$-values are derived from a two-tailed Chi-squared test (* $\left.p<0.05 ;{ }^{* * * *} p<0.0001\right)$. (B) Spindle length. Data sets were compared with a two-tailed unpaired Student's t-tests $\left({ }^{*} p<0.05 ;{ }^{* *} p<0.001 ;{ }^{* * *} p<0.0001\right.$; n.s., not significant). (C) The percentage of cells containing Plo1-GFP signals on two SPBs. $p$-values are derived from the two-tailed Chi-squared test (* $p<0.05 ;{ }^{* *} p<0.01 ;{ }^{* * *} p<0.0001 ;$ n.s., not significant). (D) The percentage of cells containing one Plo1-GFP signal on the unseparated SPB. $p$-values are derived from the two-tailed Chi-squared test ( $p<0.05 ;{ }^{* * * *} p<0.0001$; n.s., not significant). (E) Representative images of cells containing Plo1-GFP signals on the SPB. Cell peripheries are indicated by dotted lines and areas containing SPBs (squares) are enlarged in the three panels on the right-hand side. Scale bars, $10 \mu \mathrm{m}$ (left) and $1 \mu \mathrm{m}$ (right). 


\subsection{Alp14, But Not Dis1, Promotes Microtubule Nucleation}

It is known that in fission yeast, as in other species, the homologue of polo-like kinase Plo1 is localised to the SPB from the end of G2 phase until anaphase; fluorescently tagged Plo1 serves as a reliable marker for early to mid-mitosis [31-33]. Observation of Plo1-GFP at SPBs in various strains reinforced our previous results, showing collaborative action between Alp14 and Dis1 (see Figure 2A,B). The percentage of cells possessing Plo1-GFP signals on the two SPBs was increased in dis1 $\Delta$ or alp $14 \Delta$ compared to wild-type cells ( $18 \%$ or $24 \%$ respectively vs $8 \%$ for wild-type cells) (Figure $2 \mathrm{C}$ ). Although the percentage of these Plo1-GFP positive cells was not significantly altered (10\%) in the alp14-26 mutant, alp14-26dis1 $\Delta$ cells showed a substantial increase (35\%) (Figure 2C). This result supports the notion that Alp14 and Dis1 collaborate to promote spindle elongation.

Interestingly, we found that the percentage of cells displaying a single Plo1-GFP signal on the unseparated SPB was the same between wild-type and dis $1 \Delta$ cells $(<1 \%$, n.s.), and further, the percentage did not increase significantly in alp14-26dis1 $\Delta$ cells compared to alp14-26 cells (15-16\%, n.s.) (Figure 2D). As most of these cells $(85 \%, 35 / 41)$ did not contain interphase MTs but instead dot-like MT signals were observed around the SPB (Figure 2E), they were posited to be in an early mitotic stage. Note that the intensity of these dots appeared to be severely reduced in alp14-26 compared to wild-type cells by visual inspection, consistent with the notion that Alp14 is required for MT nucleation [17,24]. Thus, Alp14 and Dis1 are required for proper spindle elongation; however only Alp14 promotes MT nucleation.

\subsection{Microtubule Intensities Are Reduced by Simultaneous Inactivation of Alp14 and Dis1}

The data discussed above indicate alp14-26dis1 $\Delta$ cells spend a longer period of time during an early mitotic stage with shorter spindle length. To study the defects associated with this delay, we measured the intensity of spindle MTs in individual cells. We found that spindle intensity was markedly reduced in the alp14-26dis1 $\Delta$ mutant ( $\sim 5 \%$ reduction compared to wild-type cells, Figure 3A,B). In either of alp14-26 or alp $14 \Delta$ cells, spindle intensities were also decreased compared to wild-type cells $(\sim 30 \%$ reduction), but higher than those in the alp14-26dis1 $\Delta$ mutant (Figure 3A,B). This result corroborates the notion that Alp14 and Dis1 are together yet independently required for spindle assembly and elongation. It is worth noting that as spindle intensity of dis $1 \Delta$ cells did not display an obvious reduction, Alp14 appears to play a compensatory role in the maintenance of spindle intensity in the absence of Dis1, which is also the case for spindle length control (see Figure 2B). 

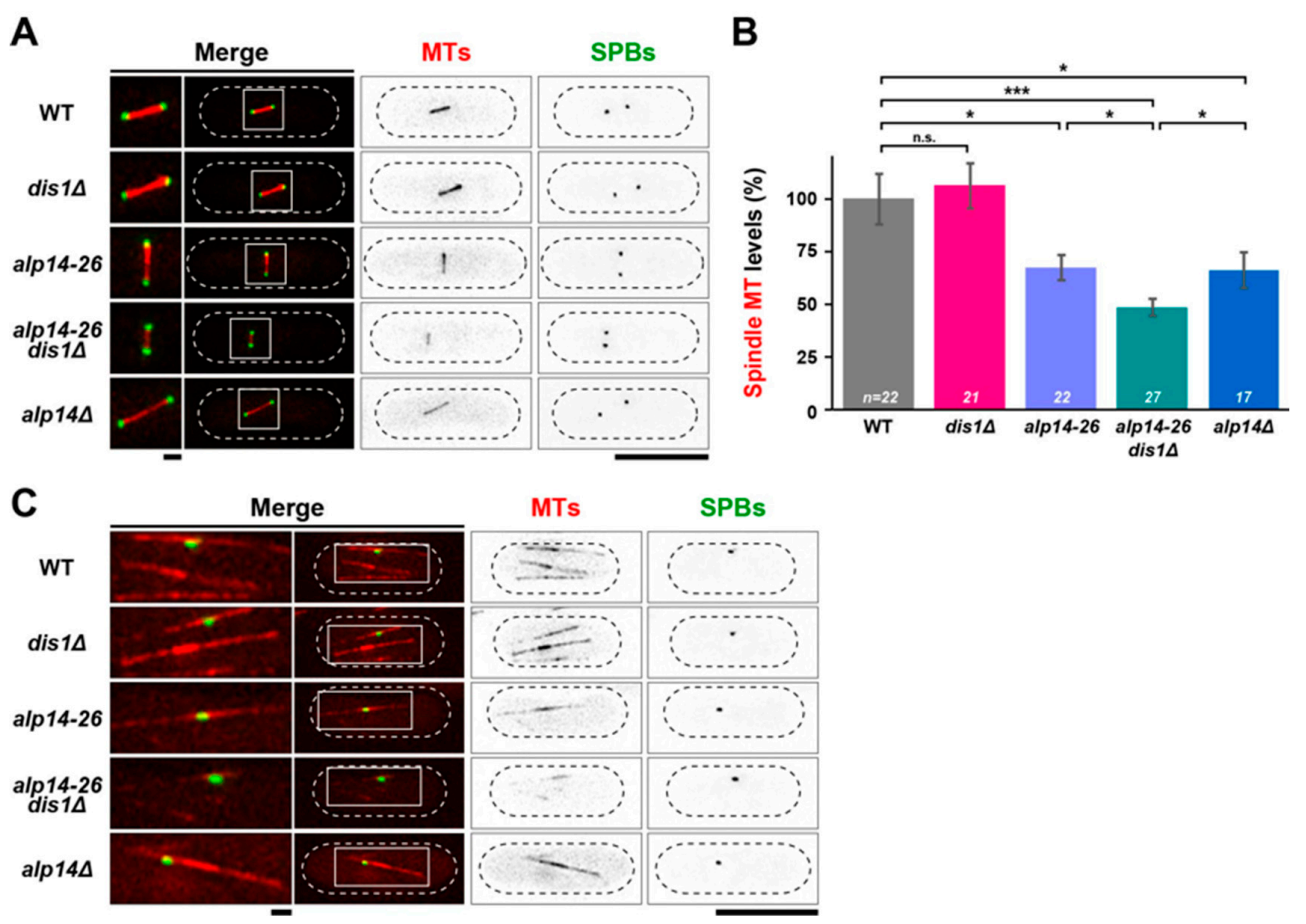

Figure 3. Microtubule intensities are reduced in alp14-26dis1 $\Delta$ in an additive fashion compared to each single mutant. Exponentially growing cells at $27^{\circ} \mathrm{C}$ were shifted to $36{ }^{\circ} \mathrm{C}$ for $2 \mathrm{~h}$. Spindle MTs (mCherry-Atb2; red) and SPBs (Cut12-GFP; green) were visualised. (A) Representative images of mitotic spindles. Cell peripheries are indicated by dotted lines and areas containing spindle MTs (squares) are enlarged in the left-hand side panels. (B) Quantification of spindle MT intensities. Fluorescence intensities of mCherry-Atb2 were measured in the indicated strains. The values of wild-type cells were taken as $100 \%$ and used for comparison to other strains. All $p$-values were obtained from a two-tailed unpaired Student's t test. Data are presented as the means \pm SEM $\left(\geq 17\right.$ cells). $\left({ }^{*} p<0.05 ;{ }^{* * *} p<0.001\right.$; n.s., not significant.) (C) Representative images of interphase MTs. Images were taken from samples incubated at $27^{\circ} \mathrm{C}$. Cell peripheries are indicated by dotted lines and areas containing interphase MTs (squares) are enlarged in the left-hand side panels. Scale bars, $1 \mu \mathrm{m}$ (left) and $10 \mu \mathrm{m}$ (right).

Previous work found that Alp14 is required for MT nucleation as well as MT growth during interphase [17,24]. By contrast, Dis1 is involved in the stabilisation of MT bundles during interphase [34]. Given these previous findings, we were interested in the structures of interphase MTs in alp14-26dis1 $\Delta$ double mutants. Visual inspection showed that alp14-26dis1 $\Delta$ mutant cells exhibit remarkably faint interphase MT structures; these MTs were much shorter and dimmer compared to wild-type and each single mutant (Figure 3C). Therefore, Alp14 and Dis1 in concert promote growth and stability of microtubules during both interphase and mitosis.

\subsection{Short Spindles Often Collapse in alp14-26dis1 $\triangle$ Cells, Leading to a Lethal "Cut" Phenotype}

We next investigated the behaviour of live spindle MTs by time-lapse microscopy. This analysis uncovered that many mitotic alp14-26dis1 $\Delta$ cells failed to elongate spindles properly; in $78 \%$ (21/27) of mitotic cells, the two SPBs remained in close proximity for a prolonged period of time (Figure $4 \mathrm{~A}, \mathrm{~B}$ ). This result mirrored those obtained from still images in our initial experiments (see Figure $2 B, C$ ). Close inspection of live images revealed that in these cells the SPBs exhibited a "breathing" or "'collapse" behaviour: the distance between the two SPBs fluctuated (Figure $4 \mathrm{C}$, top) or was shortened substantially (Figure 4C, bottom), respectively. In wild-type cells, we have never observed this defect $(n=20)$. Hence, Alp14 and Dis1 are required for the maintenance of spindle MT integrity.

Additionally, we found that alp14-26dis1 $\Delta$ exhibited a lethal "cut" phenotype (Figure 4D), in which septation occurred in the absence of proper chromosome segregation [35]. Although we have 
not observed the cut phenotype in wild-type cells $(n=35)$, all the single mutants displayed this defect to varying degrees, though the frequency was much lower compared to alp14-26dis1 $\Delta$ double mutant cells (6-19\% vs $31 \%$, respectively) (Figure $4 \mathrm{E}$ ). Thus, the reason for lethality of alp14-26dis $1 \Delta$ cells incubated at the restrictive temperature is attributable to untimely septation in the absence of proper sister chromatid segregation.

A

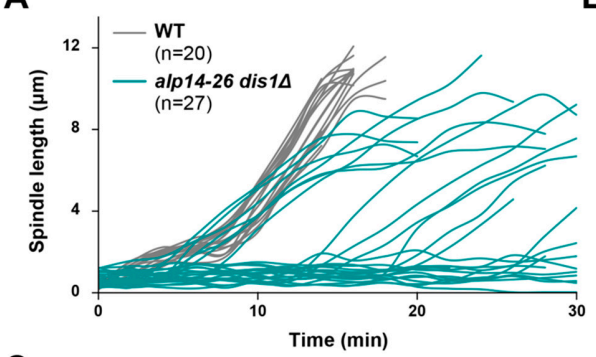

B

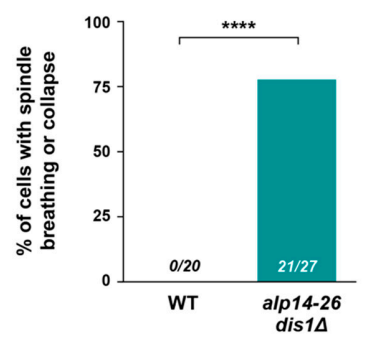

C
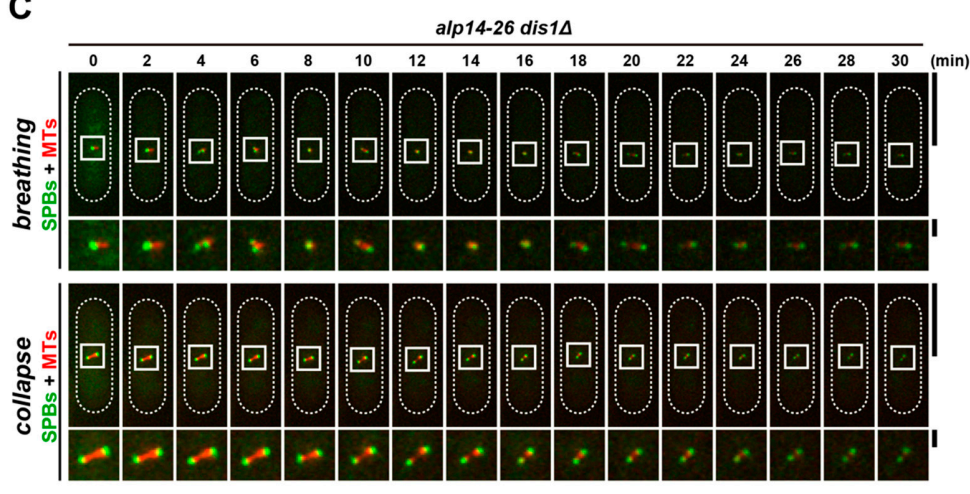

D

E
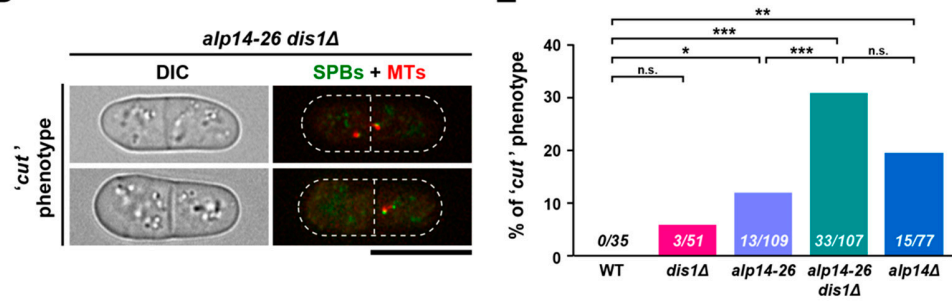

Figure 4. Short spindles are often collapsed in alp14-26dis1 $\Delta$, leading to the lethal "cut" phenotype. Exponentially growing cells at $27^{\circ} \mathrm{C}$ were shifted to $36^{\circ} \mathrm{C}$ for $2 \mathrm{~h}$. Spindle MTs (mCherry-Atb2; red) and SPBs (Cut12-GFP (A-C) or Plo1-GFP (D and E); green) were visualised. (A) Plots of spindle length over time. Spindle length (the distance between SPBs) obtained from live cell imaging was measured over time in wild-type (grey, $n=20$ ) and alp14-26 dis1 $\Delta$ cells (teal, $n=27$ ). (B) Percentage of cells displaying spindle breathing or collapse. The sample numbers are shown $(n=20$ for wild-type

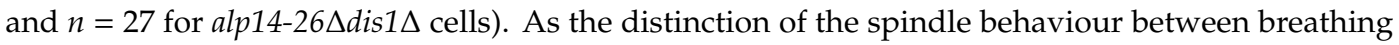
and collapse is sometimes equivocal, these two phenotypes are combined in this graph. The $p$-value is derived from a two-tailed Chi-squared test $(* * * * p<0.0001)$. (C) Time-lapse images of a mitotic alp14-26dis1 $\Delta$ cell displaying spindle breathing or collapse. Representative images of breathing (top) or collapse (bottom) are shown. Images were taken at 2 min intervals after $2 \mathrm{~h}$ incubation at $36^{\circ} \mathrm{C}$. Cell peripheries are indicated with dotted lines (the top part of each row). The areas containing SPBs and spindle microtubules are marked by square boxes and are enlarged (the bottom part of each row). Scale bars, $10 \mu \mathrm{m}$ (top) and $1 \mu \mathrm{m}$ (bottom). (D) Representative images of alp14-26 $\Delta$ dis1 $\Delta$ cells exhibiting the "cut" phenotype. Scale bar, $10 \mu \mathrm{m}$. (E) The percentage of cells displaying the "cut" phenotype. All $p$-values are derived from a two-tailed Chi-squared test ${ }^{*} p<0.05 ;{ }^{* *} p<0.01$; ${ }^{* * *} p<0.001 ;$ n.s., not significant). 


\subsection{Alp14 and Dis1 Are Not Functionally Exchangeable}

Our results thus far indicate that the two fission yeast XMAP215/TOG paralogues collaborate to ensure the growth and stability of spindle MTs. Previously, we showed that overproduction of alp $14^{+}$is capable of rescuing the cold sensitivity of $d i s 1 \Delta$, and overproduction of dis $1^{+}$suppresses the ts defect of alp $14 \Delta$ [14]. In addition, dis $1 \Delta$ alp $14 \Delta$ double deletion is synthetically lethal at temperatures at which single deletion strains are viable [18]. These results suggest that Alp14 and Dis1 are functionally exchangeable paralogues; therefore, we were interested in understanding if these two proteins are replaceable at the endogenous level (without overproduction).

The most notable difference between Alp14 and Dis1 is their cellular localisation during mitosis. Alp14 is first localised to the SPB, followed by translocation to the mitotic spindle and movement towards the kinetochore as spindles elongate and capture it [36]. Dis1 is localised to the kinetochore first and loaded onto the mitotic spindle only at a later mitotic stage; importantly, Dis1 is not localised to the SPB $[16,20,37]$. One possible scenario is that once Dis1 is recruited to the SPB, it may be possible to functionally replace Alp14. To address this notion, we implemented the GFP-GFP-binding protein (GBP) protein targeting system [38]. To this end, alp $7 \Delta$, alp $14 \Delta$ and wild-type strains were constructed that carried Dis1-GFP and GBP-Alp4 (Figure 5A); Alp4/GCP2 is a core component of the $\gamma$-TuC that is constitutively localised to the SPB [39]. To visualise GBP-Alp4, it was also tagged with the fluorescent protein mCherry (GBP-mCherry-Alp4). Tethering Dis1 to the SPB was successful in all strains (Figure 5B). However, assessment of the growth of these strains indicated that forced recruitment of Dis1 to the SPB was not sufficient in the absence of Alp7 or Alp14; these strains remained ts like alp $7 \Delta$ or alp $14 \Delta$ strains containing only Dis1-GFP in the absence of GBP-mCherry-Alp4 (Figure 5C). It is of note that Dis1-GFP in the presence of GBP-mCherry-Alp4 was functional, as the corresponding wild-type construct normally formed colonies at either $22^{\circ} \mathrm{C}$ or $36{ }^{\circ} \mathrm{C}$ (Figure 5C). T hus, a simple recruitment of Dis1 to the SPB is not sufficient to replace the functionality of Alp14. 
A

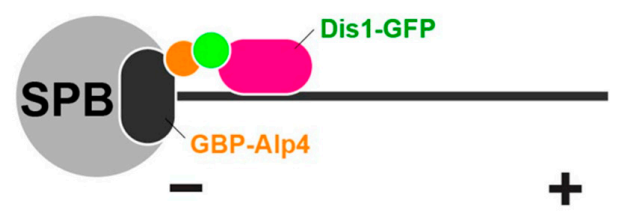

B

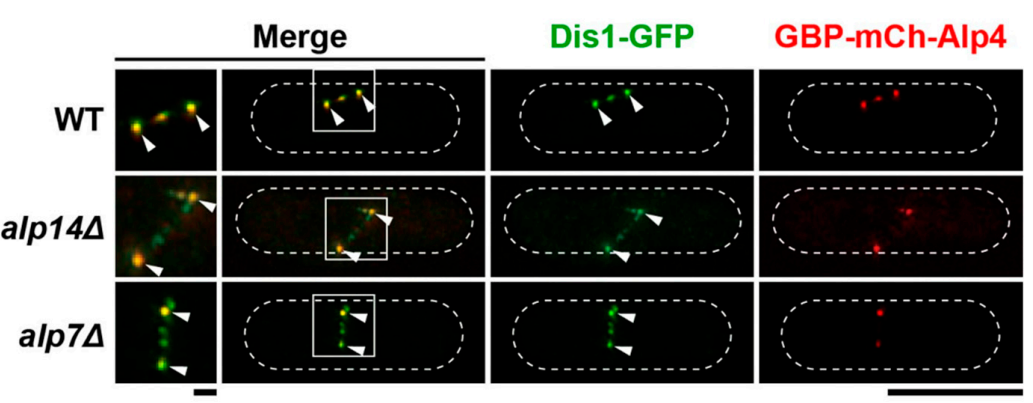

C

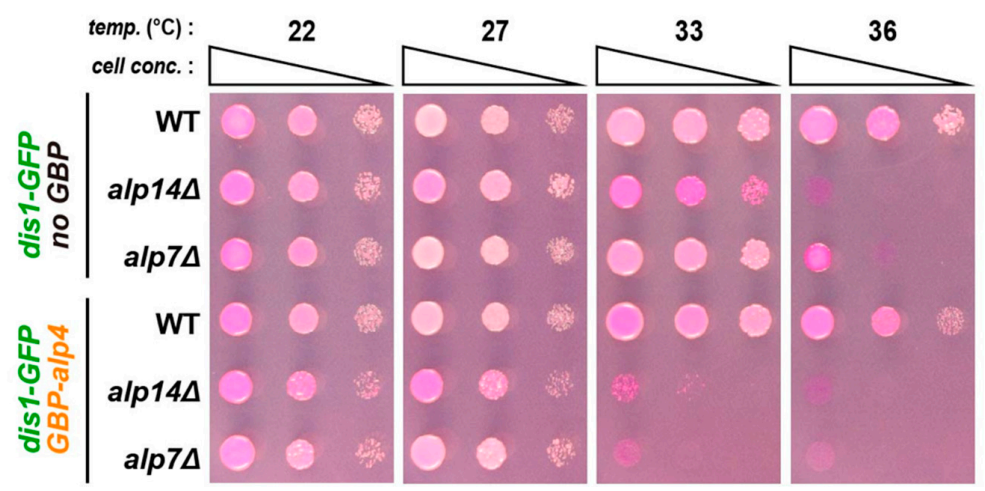

Figure 5. SPB-tethered Dis1 is incapable of rescuing alp14A. (A) A schematic illustration of a strategy for tethering Dis1 to the SPB. (B) Visualisation of Dis1-GFP localisation in strains containing GBP-mCherry-Alp4. Cell peripheries are indicated with dotted lines and areas containing spindle MTs (squares) are enlarged in the left-hand side panels. Note that in addition to SPB localisation (arrowheads), some fractions of Dis1-GFP are localised to additional dots between the two SPBs. This location is most likely to be the kinetochore, to which Dis1 is normally localised during mitosis [15,20,37]. Scale bars, $1 \mu \mathrm{m}$ (left) and $10 \mu \mathrm{m}$ (right). (C) Spot test. Indicated strains were serially (10-fold) diluted, spotted onto rich YE5S plates containing Phloxine B and incubated at the indicated temperatures for 2-3 d.

Next, the converse experiment was performed; we tethered Alp14 to the kinetochore in a dis1 $\Delta$ strain. To do so, we exploited Mis12-GBP-mCherry (Figure 6A), a constitutive component of the kinetochore [40]. Alp14-GFP was localised to the kinetochore during mitosis in all strains (Figure 6B). Growth assays revealed that Alp14-GFP and Mis12-GBP-mCherry could not alleviate cold sensitivity of dis1 $\Delta$ cells (Figure 6C), suggesting that kinetochore-tethered Alp14 cannot compensate for the loss of Dis1. Alp14-GFP in the presence of Mis12-GBP-mCherry is functional, as wild-type cells containing these two fluorescent proteins could form normal colonies at all temperatures assessed (Figure 6C). Taken together, the results shown here indicate that the spatial difference does not account for the functional specification between Alp14 and Dis1. Therefore, we conclude that although Alp14 and Dis1 are structurally related MT polymerases and act in collaborative fashion, these two MAPs are functionally divergent and execute their individual roles in a spatially distinct manner. 

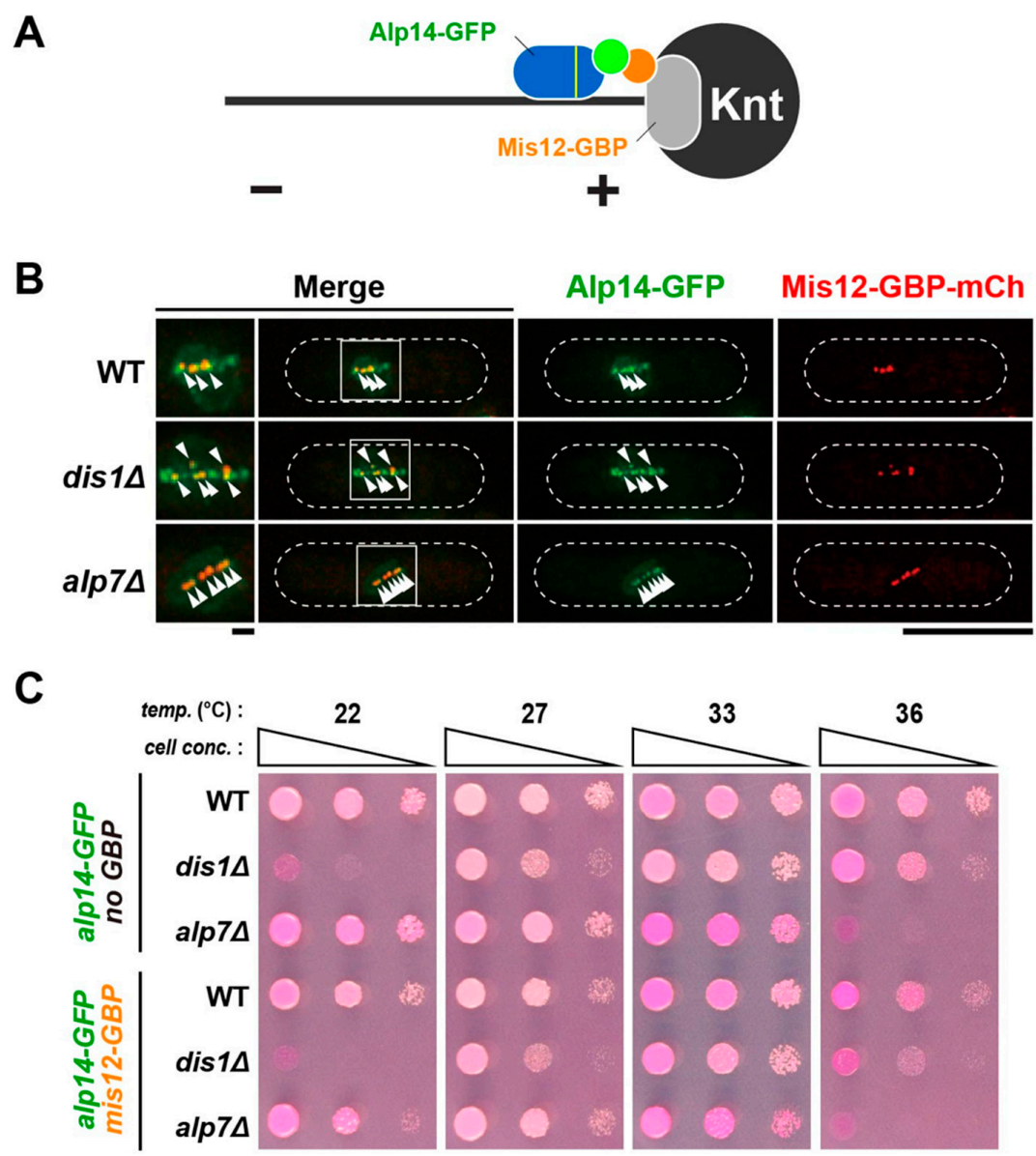

Figure 6. Kinetochore-tethered Alp14 is incapable of rescuing dis1 $\Delta$. (A) A schematic illustration of a strategy for tethering Alp14 to the kinetochore (Knt). To ensure nuclear entry of Alp14, a canonical nuclear localisation signal (NLS) sequence [41] was added together with GFP to the C terminus of Alp14 (Alp14 ${ }^{\mathrm{NLS}}$-GFP) [42]. (B) Visualisation of Alp14 ${ }^{\mathrm{NLS}}$-GFP localisation in strains containing Mis12-GBP-mCherry. Cell peripheries are indicated with dotted lines and areas containing spindle MTs (squares) are enlarged in the left-hand side panels. Kinetochores are marked with arrowheads. Note that Alp14 ${ }^{\text {NLS }}$-GFP and Mis12-GBP-mCherry do not completely colocalise; additional Alp14 ${ }^{\text {NLS }}$-GFP dots are observed in a dis1 $\Delta$ cell. This could represent the SPBs, to which Alp14 is normally localised [15,43]. Scale bars, $1 \mu \mathrm{m}$ (left) and $10 \mu \mathrm{m}$ (right). (C) Spot test. Indicated strains were serially (10-fold) diluted, spotted onto rich YE5S plates containing Phloxine B and incubated at the indicated temperatures for 2-3 d.

\section{Discussion}

In this study, we have explored the functional conservation and diversification of two fission yeast XMAP215/TOG paralogues Alp14 and Dis1. We show that simultaneous inactivation of Alp14 and Dis1 has an adverse impact on spindle assembly in an additive fashion; double mutant cells arrest in early mitosis with very short, fragile spindles. These cells often undergo spindle collapse, leading to a lethal cut phenotype. Intriguingly, mutual spatial replacement between these two MAPs is unable to complement the function for the other. Therefore, in opposition to a simple scenario, our results have illuminated the intrinsic functional specification between Alp14 and Dis1 (Figure 7). 


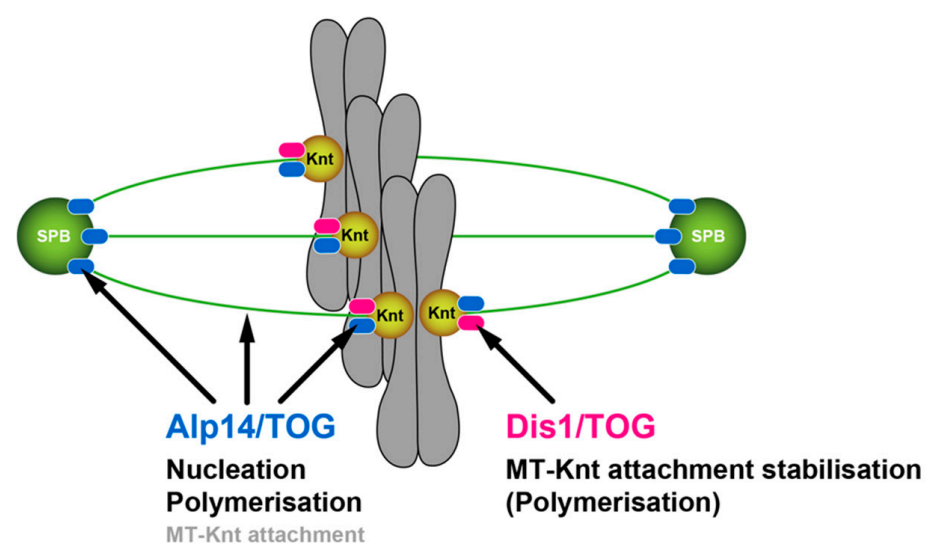

Figure 7. A model of the distinct roles for two XMAP215/TOG proteins in fission yeast. During mitosis, Alp14/TOG, by forming a complex with Alp7/TACC [19], is first recruited to the SPB, where it promotes spindle MT assembly through two different mechanisms: MT nucleation and polymerisation [24]. Alp14 is then transported along spindle MTs towards the kinetochore (Knt), where it binds the Ndc80 kinetochore component [23]. Accordingly, Alp14 is required for MT nucleation, polymerisation and stabilisation. By contrast, Dis1/TOG is recruited to the kinetochore-MT interface through interaction with Ndc80 and Mal3/EB1 without being localised to the SPB [16,20]. Dis1 plays a crucial role in the establishment of stable kinetochore-spindle attachment. These two MAPs have undergone intrinsic functional diversifications, thereby being unreplaceable with each other even if Alp14 and Dis1 are artificially tethered to the kinetochore and the SPB respectively.

\subsection{Alp14 and Dis1 Have Evolved to Execute Functionally Non-Exchangeable Roles}

In normal cells, Alp14 is recruited to the mitotic SPB in the nucleus where it promotes spindle assembly [19,43-46]. It is known that Alp7 mediates this translocation [47,48] and Alp7 function can be bypassed through direct targeting of Alp14 to the nuclear SPB [42]. Importantly, we show here that the analogous tethering for Dis1 is not sufficient to circumvent Alp14 function. Conversely, tethering Alp14 to the kinetochore, the critical structure at which Dis1 plays a role in stabilisation of kinetochore-spindle attachment [20], is incapable of bypassing the need for Dis1. Together, these results have established that Alp14 and Dis1 are functionally non-exchangeable. This conclusion is in line with phylogenetic analyses, in which Alp14 and Dis1 split relatively early during fungi diversification: these two genes are diversified before the emergence of various fungi species yet after fungi separate from animals [9]. It is worth mentioning that unlike Alp14 and Dis1 MT polymerases, two kinesin-14 members in fission yeast, Pkl1 and Klp2, are functionally replaceable by artificial targeting of Klp2 to the SPB to which Pkl1, but not Klp2, is normally localised [49].

An interesting question is then how does a single member of the XMAP215/TOG family in other organisms perform the equivalent roles of Alp14 and Dis1? It is known that in animals including humans, a stable interaction between XMAP215/TOG members and TACC homologues is widely conserved like Alp14 and Alp7/TACC [8,50]. Intriguingly, in metazoans, multiple TACC homologues exist, by which individual TACC members might execute specific roles in MT organisation by forming distinct complexes with XMAP215/TOG [50]. In addition, it is known that animal XMAP215/TOG interacts with EB1 through adaptor proteins: Sentin in flies [51] and SLAIN in humans [52], and XMAP215 and EB1 synergistically increase MT growth rate at the plus end [53]. This may underpin the role of animal XMAP215/TOG in the stabilisation of proper kinetochore-spindle attachment, like the Dis1-Mal3 complex [16]. As aforementioned, Alp14 and Dis1 are evolutionarily diverged only after the fungi kingdom separated from the animal kingdom [9]. Hence, animal XMAP215/TOG members, like their ancestor, may retain dual activities that Alp14 and Dis1 each execute. Alternatively, albeit not mutually exclusive, Dis1 and/or Alp14 may acquire unique roles specific for fission yeast. 


\subsection{Dis1 May Be a Specialised Regulator of Microtubule Dynamics at the Kinetochore-Microtubule Interface}

It is known that metazoan XMAP215/TOG, budding yeast Stu2 and fission yeast Alp14 are critical factors for MT nucleation, in addition to MT polymerisation, at the centrosome/SPB [24,25,54,55]. As for Dis1, this protein is neither recruited to the SPB $[15,20]$ nor capable of replacing the role of Alp14 even if it is targeted to this site. Accordingly, we consider that unlike other members of the XMAP215/TOG family, Dis1 has lost its MT nucleating activity through evolution. The fact that in the alp14-26dis1 $\Delta$ double mutant very early mitotic cells accumulate indicates that Dis1 plays a role in the stabilisation of spindle MTs from this early mitotic stage.

Previous studies have highlighted unexpected, unique functions of Dis1 compared to other XMAP215/TOG members. For instance, during the first meiotic division, Dis1 plays a role in microtubule shortening to pull kinetochores polewards: this protein appears to promote MT depolymerisation under this condition [26]. In addition, we recently showed that Dis1 potentiates spindle shortening in the absence of the Klp5-Klp6 kinesin-8 complex to ensure kinetochore capture by spindle MTs for proper mitotic progression [27]. Furthermore, Dis1, but not Alp14, plays a role in epigenetic regulation at centromeric chromatin [56]. Overall, Dis1 appears committed to a specific task at the kinetochore-MT interface during mitosis, thereby stabilising proper attachment [20]. Identification of the domains and amino acid residues within Alp14 and Dis1 that delimit Alp14- or Dis1-specific activities would be of great significance to delineate how individual members of the XMAP215/TOG family execute conserved and diversified roles and also to obtain mechanistic information regarding how this family promotes MT polymerisation and/or depolymerisation.

\section{Materials and Methods}

\subsection{Strains, Media, and Genetic Methods}

Fission yeast strains used in this study are listed in Table 1. Media, growth conditions and manipulations were performed as previously described [57]. For most of the experiments, rich YE5S liquid media and agar plates were used. Spot tests were performed by spotting 5-10 $\mu \mathrm{L}$ of cells at a concentration of $2 \times 10^{7}$ cells $/ \mathrm{mL}$ after 10-fold serial dilutions onto rich YE5S plates. Some of the YE5S plates also contained Phloxine B, a dye that accumulates in dead or dying cells and stains those colonies dark pink due to a reduced ability to pump out the dye. Plates were incubated at various temperatures from $22{ }^{\circ} \mathrm{C}$ to $36^{\circ} \mathrm{C}$ as necessary.

Table 1. Fission yeast strains used in this study.

\begin{tabular}{llll}
\hline \multicolumn{1}{c}{ Strains } & \multicolumn{1}{c}{ Genotypes } & Figures Used & \multicolumn{1}{c}{ Derivations } \\
\hline MS345 & $h^{-}$alp14::ura4 ${ }^{+}$leu1 ura4 & 1A & Our lab stock \\
\hline MA003 & $h^{+}$alp14-GFP-kanR leu1ura4 his2 & $1 \mathrm{~A}$ & Our lab stock \\
\hline MY2097 & $h^{-}$alp14-21-GFP-kanR leu1ura4 & $1 \mathrm{~A}$ & This study \\
\hline TK469 & $h^{-}$alp14-26-GFP-kanR leu1ura4 & $1 \mathrm{~A}$ & This study \\
\hline MY2099 & $h^{-}$alp14-27-GFP-kanR leu1ura4 & $1 \mathrm{~A}$ & This study \\
\hline TK475 & $h^{-}$alp14-31-GFP-kanR leu1ura4 & $1 \mathrm{~A}$ & This study \\
\hline TK484 & $h^{-}$alp14-32-GFP-kanR leu1ura4 & $1 \mathrm{~A}$ & This study \\
\hline MY2101 & $h^{-}$alp14-33-GFP-kanR leu1ura4 & $1 \mathrm{~A}$ & This study \\
\hline TK358 & $h^{-}$dis1::hphR alp14-GFP-kanR leu1 ura4 & $1 \mathrm{~A}$ & This study \\
\hline TK400 & $h^{-}$alp14-21-GFP-kanR dis1::hphR leu1 ura4 & $1 \mathrm{~A}-\mathrm{B}$ & This study \\
\hline TK405 & $h^{-}$alp14-26-GFP-kanR dis1::hphR leu1 ura4 & $1 \mathrm{~A}-\mathrm{B}$ & This study \\
\hline TK406 & $h^{-}$alp14-27-GFP-kanR dis1::hphR leu1 ura4 & $1 \mathrm{~A}-\mathrm{B}$ & This study \\
\hline
\end{tabular}


Table 1. Cont.

\begin{tabular}{|c|c|c|c|}
\hline Strains & Genotypes & Figures Used & Derivations \\
\hline TK457 & $h^{-}$alp14-31-GFP-kanR dis1::hphR leu1 ura4 & $1 \mathrm{~A}-\mathrm{B}$ & This study \\
\hline TK458 & $h^{-}$alp14-32-GFP-kanR dis1::hphR leu1 ura4 & $1 \mathrm{~A}-\mathrm{B}$ & This study \\
\hline TK459 & $h^{-}$alp14-33-GFP-kanR dis1::hphR leu1 ura4 & $1 \mathrm{~A}-\mathrm{B}$ & This study \\
\hline TK551 & $\begin{array}{l}h^{+} \text {plo1-GFP-HA-kanR aur1R-Pnda3-mCherry-atb2 leu1 ura4 } \\
\text { his2 }\end{array}$ & $2 \mathrm{~A}-\mathrm{E}, 4 \mathrm{E}$ & This study \\
\hline TK583 & $\begin{array}{l}h^{-} \text {dis1::ura4 }{ }^{+} \text {plo1-GFP-HA-kanR } \\
\text { aur1R-Pnda3-mCherry-atb2 leu1 ura4 }\end{array}$ & $2 \mathrm{~A}-\mathrm{E}, 4 \mathrm{E}$ & This study \\
\hline TK556 & $\begin{array}{l}h^{-} \text {alp14-26-myc-hphR plo1-GFP-HA-kanR } \\
\text { aur1R-Pnda3-mCherry-atb2 leu1 ura4 }\end{array}$ & $2 \mathrm{~A}-\mathrm{E}, 4 \mathrm{E}$ & This study \\
\hline TK585 & $\begin{array}{l}h^{-} \text {alp14-26-myc-hphR dis1::ura4 }{ }^{+} \text {plo1-GFP-HA-kanR } \\
\text { aur1R-Pnda3-mCherry-atb2 leu1 ura4 }\end{array}$ & 2A-E, 4D-E & This study \\
\hline TK586 & $\begin{array}{l}h^{-} \text {alp14::ura4 }{ }^{+} \text {plo1-GFP-HA-kanR } \\
\text { aur1R-Pnda3-mCherry-atb2 leu1 ura4 }\end{array}$ & $2 \mathrm{~A}-\mathrm{E}, 4 \mathrm{E}$ & This study \\
\hline MO100 & $h^{-}$cut12-GFP-ura4 ${ }^{+}$aur1R-Pnda3-mCherry-atb2 leu1 ura4 & $3 \mathrm{~A}-\mathrm{C}, 4 \mathrm{~A}-\mathrm{B}$ & Our lab stock \\
\hline TK547 & $\begin{array}{l}h^{+} \text {dis1::natR cut12-GFP-ura4 } 4^{+} \text {aur1R-Pnda3-mCherry-atb2 } \\
\text { leu1 ura4 his2 }\end{array}$ & $3 \mathrm{~A}-\mathrm{C}$ & This study \\
\hline TK580 & $\begin{array}{l}h^{+} \text {alp14-26-myc-hphR cut12-GFP-ura4 } \\
\text { aur1R-Pnda3-mCherry-atb2 leu1 ura4 }\end{array}$ & $3 \mathrm{~A}-\mathrm{C}$ & This study \\
\hline TK572 & $\begin{array}{l}h^{-} \text {alp14-26-myc-hphR dis1::natR cut12-GFP-ura4 }{ }^{+} \\
\text {aur1R-Pnda3-mCherry-atb2 leu1 ura4 }\end{array}$ & $3 \mathrm{~A}-\mathrm{C}, 4 \mathrm{~A}-\mathrm{C}$ & This study \\
\hline TK582 & $\begin{array}{l}h^{+} \text {alp14::hphR cut12-GFP-ura4 }{ }^{+} \text {aur1R-Pnda3-mCherry-atb2 } \\
\text { leu1 ura4 his2 }\end{array}$ & $3 \mathrm{~A}-\mathrm{C}$ & This study \\
\hline TK576 & $h^{-}$dis1-GFP-kanR hphR-GBP-mCherry-alp4 leu1 ura4 & $5 B-C$ & This study \\
\hline TK591 & $\begin{array}{l}h^{-} \text {alp14::ura4 }{ }^{+} \text {dis1-GFP-kanR hphR-GBP-mCherry-alp4 leu1 } \\
\text { ura4 }\end{array}$ & $5 B-C$ & This study \\
\hline TK590 & $\begin{array}{l}h^{+} \text {alp7::ura4 }{ }^{+} \text {dis1-GFP-kanR hphR-GBP-mCherry-alp4 leu1 } \\
\text { ura4 his2 }\end{array}$ & $5 B-C$ & This study \\
\hline TK578 & $h^{-}$dis1-GFP-kanR leu1 ura4 & $5 \mathrm{C}$ & This study \\
\hline TK602 & $h^{+}$alp14::ura4 $4^{+}$dis1-GFP-kanR leu1 ura4 his2 & $5 \mathrm{C}$ & This study \\
\hline MS187 & $h^{-}$alp7::ura ${ }^{+}$dis1-GFP-kanR leu1 ura4 & $5 \mathrm{C}$ & Our lab stock \\
\hline MY2021 & $\begin{array}{l}h^{-} \text {alp14-NLS-GFP-kanR mis12-GBP-6HIS-mCherry-natR } \\
\text { leu1 ura4 }\end{array}$ & $6 \mathrm{~B}-\mathrm{C}$ & This study \\
\hline MY2041 & $\begin{array}{l}h^{-} \text {dis1::hphR alp14-NLS-GFP-kanR } \\
\text { mis12-GBP-6HIS-mCherry-natR leu1 ura4 }\end{array}$ & $6 \mathrm{~B}-\mathrm{C}$ & This study \\
\hline MY2027 & $\begin{array}{l}h^{-} \text {alp7::ura4 }{ }^{+} \text {alp14-NLS-GFP-kanR } \\
\text { mis12-GBP-6HIS-mCherry-natR leu1 ura4 }\end{array}$ & $6 \mathrm{~B}-\mathrm{C}$ & This study \\
\hline MS836 & $h^{+}$alp14-NLS-GFP-kanR leu1 ura4 his2 & $6 \mathrm{C}$ & Our lab stock \\
\hline TK360 & $h^{-}$dis1::hphR alp14-NLS-GFP-kanR leu1 ura4 & $6 \mathrm{C}$ & This study \\
\hline MS838 & $h^{-}$alp7::ura4 ${ }^{+}$alp14-NLS-GFP-kanR leu1 ura4 & $6 \mathrm{C}$ & Our lab stock \\
\hline
\end{tabular}

\subsection{Preparation and Manipulation of Nucleic Acids}

Enzymes were used as recommended by the suppliers (New England Biolabs Inc. Ipswich, MA and Takara Bio Inc., Shiga, Japan). 


\subsection{Strain Construction, Gene Disruption and N-Terminal and C-Terminal Epitope Tagging}

A PCR-based gene-targeting method [58,59] was used for complete gene disruption and epitope tagging (e.g., GFP and mCherry) at the C-terminus, by which all the tagged proteins were produced under the endogenous promoter. Construction of strains containing Alp $14^{\mathrm{NLS}}$-GFP or GBP-mCherry-Alp4 was described previously [42].

\subsection{Isolation of alp14 Temperature-Sensitive Mutants in the dis1D Background}

The alp14 ts mutants were constructed by PCR-based random mutagenesis as previously reported [28,42]. A GFP and G418-resistance marker gene cassette ( $k a n R)$ was inserted in-frame prior to the stop codon of the alp14 gene (alp14-GFP-kanR). The alp14-GFP-kanR fragment extracted and purified from this strain was amplified with error-prone PCR using TaKaRa EX taq polymerase (Takara Bio Inc. Shiga, Japan). After ethanol precipitation, pooled amplified fragments were introduced into a dis1 $\Delta$ (dis1::hphR) strain and G418-resistance transformants were selected at $27^{\circ} \mathrm{C}$. We obtained 6 ts isolates from $\sim 5000 \mathrm{G} 418$ resistant colonies. These mutants were crossed with a wild-type strain and random spore analysis was performed. In all segregants, the ts phenotype co-segregated with G418and Hygromycin B-resistance. Subsequently, nucleotide sequencing was performed to determine the mutation sites in the alp14 gene of these mutants.

\subsection{Fluorescence Microscopy and Time-Lapse Live Cell Imaging}

Fluorescence microscopy images were obtained using a DeltaVision microscope system (DeltaVision Elite; GE Healthcare, Chicago, IL, USA) with a wide-field inverted epifluorescence microscope (IX71; Olympus, Tokyo, Japan) and a Plan Apochromat 60×, NA 1.42, oil immersion objective (PLAPON 60×O; Olympus Tokyo, Japan). DeltaVision image acquisition software (softWoRx 6.5.2; GE Healthcare, Chicago, IL, USA) equipped with a charge-coupled device camera (CoolSNAP HQ2; Photometrics, Tucson, AZ, USA) was used. Live cells were imaged in a glass-bottomed culture dish (MatTek Corporation, Ashland, MA, USA) coated with soybean lectin and incubated at $27^{\circ} \mathrm{C}$ or at $36^{\circ} \mathrm{C}$. The latter were cultured in rich YE5S media until mid-log phase at $27^{\circ} \mathrm{C}$ and subsequently shifted to the restrictive temperature of $36^{\circ} \mathrm{C}$ for $2 \mathrm{~h}$ before microscopic observation. To maintain cells at the proper temperature during imaging, a temperature-controlled chamber (Air Therm SMT; World Precision Instruments Inc., Sarasota, FL, USA) was used. Time-lapse imaging was performed for $30 \mathrm{~min}$ at $36^{\circ} \mathrm{C}$. Images were taken as $14-16$ sections along the z-axis at $0.2 \mu \mathrm{m}$ intervals. The sections of images acquired at each time point were compressed into a 2D projection using the DeltaVision maximum intensity algorithm. Deconvolution was applied before the 2D projection. Captured images were processed with Photoshop CS6 (version 13.0; Adobe, San Jose, CA, USA).

\subsection{Quantification of Fluorescent Signal Intensities}

For quantification of signal intensities of the fluorescent marker-tagged protein (e.g., mCherry-Atb2), 14-16 sections were taken along the z-axis at $0.2 \mu \mathrm{m}$ intervals. Projection images of maximum intensity were obtained after deconvolution, and upon subtracting background intensities only values of maximum fluorescence intensities covering the whole GFP signals within the z-sections were used for statistical data analysis.

\subsection{Statistical Data Analysis}

We used the two-tailed unpaired Student's $t$-test to evaluate the significance of differences in different strains, unless otherwise stated. All experiments were performed at least twice. Experiment sample numbers used for statistical testing were given in the corresponding figures and/or legends. We used this key for asterisk placeholders to indicate $p$-values in the figures: e.g., ${ }^{* * *}, p<0.0001$. 
Author Contributions: M.Y. and T.T. conceived experimental designs, T.K. and M.Y. performed experiments, T.T. drafted the manuscript, T.K., C.P. and M.Y. made suggestions and T.T. and C.P. finalised the manuscript.

Funding: This work was supported by the Japan Society for the Promotion of Science (JSPS) (KAKENHI Scientific Research (A) 16H02503 and the Program for Advancing Strategic International Networks to Accelerate the Circulation of Talented Researchers (S2902) to T.T. and Scientific Research (C) 19K05813 to M.Y.).

Acknowledgments: We are grateful to Heinrich Leonhardt and Gislene Pereira for providing us with plasmids used in this study.

Conflicts of Interest: The authors declare no conflict of interest.

$\begin{array}{ll}\text { Abbreviations } \\ \text { GBP } & \text { GFP-binding protein } \\ \text { MAPs } & \text { Microtubule-Associated Proteins } \\ \text { MT } & \text { Microtubule } \\ \text { NLS } & \text { Nuclear Localisation Signal } \\ \text { SPB } & \text { Spindle Pole Body } \\ \text { ts } & \text { temperature sensitive }\end{array}$

\section{References}

1. Akhmanova, A.; Steinmetz, M.O. Control of microtubule organization and dynamics: Two ends in the limelight. Nat. Rev. Mol. Cell Biol. 2015, 16, 711-726. [CrossRef] [PubMed]

2. Godinho, S.A.; Pellman, D. Causes and consequences of centrosome abnormalities in cancer. Philos. Trans. R. Soc. Lond B Biol. Sci. 2014, 369, 20130467. [CrossRef] [PubMed]

3. Sheltzer, J.M.; Amon, A. The aneuploidy paradox: Costs and benefits of an incorrect karyotype. Trends Genet. 2011, 27, 446-453. [CrossRef] [PubMed]

4. Mitchison, T.; Kirschner, M. Dynamic instability of microtubule growth. Nature 1984, 312, 237-242. [CrossRef] [PubMed]

5. Desai, A.; Mitchison, T.J. Microtubule polymerization dynamics. Annu. Rev. Cell Dev Biol. 1997, $13,83-117$. [CrossRef]

6. Ohkura, H.; Garcia, M.A.; Toda, T. Dis1/TOG universal microtubule adaptors - one MAP for all? J. Cell Sci. 2001, 114, 3805-3812.

7. Kinoshita, K.; Habermann, B.; Hyman, A.A. XMAP215: A key component of the dynamic microtubule cytoskeleton. Trends Cell Biol. 2002, 12, 267-273. [CrossRef]

8. Al-Bassam, J.; Chang, F. Regulation of microtubule dynamics by TOG-domain proteins XMAP215/Dis1 and CLASP. Trends Cell Biol. 2011, 21, 604-614. [CrossRef]

9. Gard, D.L.; Becker, B.E.; Josh Romney, S. MAPping the eukaryotic tree of life: Structure, function, and evolution of the MAP215/Dis1 family of microtubule-associated proteins. Int. Rev. Cytol. 2004, 239, 179-272.

10. Gard, D.L.; Kirschner, M.W. A microtubule-associated protein from Xenopus eggs that specifically promotes assembly at the plus-end. J. Cell Biol. 1987, 105, 2203-2215. [CrossRef]

11. Brouhard, G.J.; Stear, J.H.; Noetzel, T.L.; Al-Bassam, J.; Kinoshita, K.; Harrison, S.C.; Howard, J.; Hyman, A.A. XMAP215 is a processive microtubule polymerase. Cell 2008, 132, 79-88. [CrossRef] [PubMed]

12. Al-Bassam, J.; van Breugel, M.; Harrison, S.C.; Hyman, A. Stu2p binds tubulin and undergoes an open-to-closed conformational change. J. Cell Biol. 2006, 172, 1009-1022. [CrossRef] [PubMed]

13. Al-Bassam, J.; Larsen, N.A.; Hyman, A.A.; Harrison, S.C. Crystal structure of a TOG domain: Conserved features of XMAP215/Dis1-family TOG domains and implications for tubulin binding. Structure 2007, 15, 355-362. [CrossRef]

14. Garcia, M.A.; Vardy, L.; Koonrugsa, N.; Toda, T. Fission yeast ch-TOG/XMAP215 homologue Alp14 connects mitotic spindles with the kinetochore and is a component of the Mad2-dependent spindle checkpoint. EMBO J. 2001, 20, 3389-3401. [CrossRef] 
15. Nakaseko, Y.; Goshima, G.; Morishita, J.; Yanagida, M. M phase-specific kinetochore proteins in fission yeast microtubule-associating Dis1 and Mtc1 display rapid separation and segregation during anaphase. Curr. Biol. 2001, 11, 537-549. [CrossRef]

16. Matsuo, Y.; Maurer, S.P.; Yukawa, M.; Zakian, S.; Singleton, M.R.; Surrey, T.; Toda, T. An unconventional interaction between Dis1/TOG and Mal3/EB1 in fission yeast promotes the fidelity of chromosome segregation. J. Cell Sci. 2016, 129, 4592-4606. [CrossRef]

17. Al-Bassam, J.; Kim, H.; Flor-Parra, I.; Lal, N.; Velji, H.; Chang, F. Fission yeast Alp14 is a dose dependent plus end tracking microtubule polymerase. Mol. Biol. Cell 2012, 23, 2878-2890. [CrossRef]

18. Garcia, M.A.; Koonrugsa, N.; Toda, T. Spindle-kinetochore attachment requires the combined action of Kin I-like Klp5/6 and Alp14/Dis1-MAPs in fission yeast. EMBO J. 2002, 21, 6015-6024. [CrossRef]

19. Sato, M.; Vardy, L.; Angel Garcia, M.; Koonrugsa, N.; Toda, T. Interdependency of fission yeast Alp14/TOG and coiled coil protein Alp7 in microtubule localization and bipolar spindle formation. Mol. Biol. Cell 2004, 15, 1609-1622. [CrossRef]

20. Hsu, K.S.; Toda, T. Ndc80 internal loop interacts with Dis1/TOG to ensure proper kinetochore-spindle attachment in fission yeast. Curr. Biol. 2011, 21, 214-220. [CrossRef]

21. Amin, M.A.; Agarwal, S.; Varma, D. Mapping the kinetochore MAP functions required for stabilizing microtubule attachments to chromosomes during metaphase. Cytoskeleton (Hoboken) 2019, 76, 398-412. [CrossRef] [PubMed]

22. Tang, N.H.; Toda, T. Ndc80 Loop as a protein-protein interaction motif. Cell Div. 2013, 8, 2. [CrossRef] [PubMed]

23. Tang, N.H.; Takada, H.; Hsu, K.S.; Toda, T. The internal loop of fission yeast Ndc80 binds Alp7/TACC-Alp14/TOG and ensures proper chromosome attachment. Mol. Biol. Cell 2013, 24, 1122-1133. [CrossRef] [PubMed]

24. Flor-Parra, I.; Iglesias-Romero, A.B.; Chang, F. The XMAP215 ortholog Alp14 promotes microtubule nucleation in fission yeast. Curr. Biol. 2018, 28, 1681-1691. [CrossRef]

25. Thawani, A.; Kadzik, R.S.; Petry, S. XMAP215 is a microtubule nucleation factor that functions synergistically with the gamma-tubulin ring complex. Nat. Cell Biol. 2018, 20, 575-585. [CrossRef]

26. Kakui, Y.; Sato, M.; Okada, N.; Toda, T.; Yamamoto, M. Microtubules and Alp7-Alp14 (TACC-TOG) reposition chromosomes before meiotic segregation. Nat. Cell Biol. 2013, 15, 786-796. [CrossRef]

27. Pinder, C.L.; Matsuo, Y.; Maurer, S.P.; Toda, T. Kinesin-8 and Dis1/TOG collaborate to limit spindle elongation from prophase to anaphase A for proper chromosome segregation in fission yeast. J. Cell Sci. 2019, 132, 1-15. [CrossRef]

28. Tang, N.H.; Fong, C.S.; Masuda, H.; Jourdain, I.; Yukawa, M.; Toda, T. Generation of temperature sensitive mutations with error-prone PCR in a gene encoding a component of the spindle pole body in fission yeast. Biosci. Biotechnol. Biochem. 2019, 83, 1717-1720. [CrossRef]

29. Toda, T.; Adachi, Y.; Hiraoka, Y.; Yanagida, M. Identification of the pleiotropic cell division cycle gene NDA2 as one of two different $\alpha$-tubulin genes in Schizosaccharomyces pombe. Cell 1984, 37, 233-242. [CrossRef]

30. Nabeshima, K.; Nakagawa, T.; Straight, A.F.; Murray, A.; Chikashige, Y.; Yamashita, Y.M.; Hiraoka, Y.; Yanagida, M. Dynamics of centromeres during metaphase-anaphase transition in fission yeast: Dis1 is implicated in force balance in metaphase bipolar spindle. Mol. Biol. Cell 1998, 9, 3211-3225. [CrossRef]

31. Mulvihill, D.P.; Petersen, J.; Ohkura, H.; Glover, D.M.; Hagan, I.M. Plo1 kinase recruitment to the spindle pole body and its role in cell division in Schizosaccharomyces pombe. Mol. Biol. Cell 1999, 10, 2771-2785. [CrossRef] [PubMed]

32. Grallert, A.; Patel, A.; Tallada, V.A.; Chan, K.Y.; Bagley, S.; Krapp, A.; Simanis, V.; Hagan, I.M. Centrosomal MPF triggers the mitotic and morphogenetic switches of fission yeast. Nat. Cell Biol. 2013, 15, 88-95. [CrossRef] [PubMed]

33. Bähler, J.; Steever, A.B.; Wheatley, S.; Wang, Y.-1.; Pringle, J.R.; Gould, K.L.; McCollum, D. Role of polo kinase and Mid1p in determining the site of cell division in fission yeast. J. Cell Biol. 1998, 143, 1603-1616. [CrossRef]

34. Roque, H.; Ward, J.J.; Murrells, L.; Brunner, D.; Antony, C. The fission yeast XMAP215 homolog Dis1p is involved in microtubule bundle organization. PLoS ONE 2010, 5, e14201. [CrossRef]

35. Yanagida, M. Fission yeast cut mutations revisited: Control of anaphase. Trends Cell Biol. 1998, 8, 144-149. [CrossRef] 
36. Sato, M.; Toda, T. Space shuttling in the cell: Nucleocytoplasmic transport and microtubule organization during the cell cycle. Nucleus 2010, 1, 231-236. [CrossRef]

37. Aoki, K.; Nakaseko, Y.; Kinoshita, K.; Goshima, G.; Yanagida, M. Cdc2 phosphorylation of the fission yeast Dis1 ensures accurate chromosome segregation. Curr. Biol. 2006, 16, 1627-1635. [CrossRef]

38. Rothbauer, U.; Zolghadr, K.; Muyldermans, S.; Schepers, A.; Cardoso, M.C.; Leonhardt, H. A versatile nanotrap for biochemical and functional studies with fluorescent fusion proteins. Mol. Cell Proteomics 2008, 7, 282-289. [CrossRef]

39. Vardy, L.; Toda, T. The fission yeast $\gamma$-tubulin complex is required in G1 phase and is a component of the spindle assembly checkpoint. EMBO J. 2000, 19, 6098-6111. [CrossRef]

40. Goshima, G.; Saitoh, S.; Yanagida, M. Proper metaphase spindle length is determined by centromere proteins Mis12 and Mis6 required for faithful chromosome segregation. Genes Dev. 1999, 13, 1664-1677. [CrossRef]

41. Kalderon, D.; Roberts, B.L.; Richardson, W.D.; Smith, A.E. A short amino acid sequence able to specify nuclear location. Cell 1984, 39, 499-509. [CrossRef]

42. Yukawa, M.; Kawakami, T.; Okazaki, M.; Kume, K.; Tang, N.H.; Toda, T. A microtubule polymerase cooperates with the kinesin-6 motor and a microtubule cross-linker to promote bipolar spindle assembly in the absence of kinesin-5 and kinesin-14 in fission yeast. Mol. Biol. Cell 2017, 28, 3647-3659. [CrossRef] [PubMed]

43. Sato, M.; Toda, T. Alp7/TACC is a crucial target in Ran-GTPase-dependent spindle formation in fission yeast. Nature 2007, 447, 334-337. [CrossRef] [PubMed]

44. Okada, N.; Toda, T.; Yamamoto, M.; Sato, M. CDK-dependent phosphorylation of Alp7-Alp14 (TACC-TOG) promotes its nuclear accumulation and spindle microtubule assembly. Mol. Biol. Cell 2014, 25, 1969-1982. [CrossRef]

45. Sato, M.; Okada, N.; Kakui, Y.; Yamamoto, M.; Yoshida, M.; Toda, T. Nucleocytoplasmic transport of Alp7/TACC organizes spatiotemporal microtubule formation in fission yeast. EMBO Rep. 2009, 10, 1161-1167. [CrossRef]

46. Ling, Y.C.; Vjestica, A.; Oliferenko, S. Nucleocytoplasmic shuttling of the TACC protein Mia1p/Alp7p is required for remodeling of microtubule arrays during the cell cycle. PLoS ONE 2009, 4, e6255. [CrossRef]

47. Tang, N.H.; Okada, N.; Fong, C.S.; Arai, K.; Sato, M.; Toda, T. Targeting Alp7/TACC to the spindle pole body is essential for mitotic spindle assembly in fission yeast. FEBS Lett. 2014, 588, 2814-2821. [CrossRef]

48. Zheng, F.; Li, T.; Jin, D.Y.; Syrovatkina, V.; Scheffler, K.; Tran, P.T.; Fu, C. Csi1p recruits alp7p/TACC to the spindle pole bodies for bipolar spindle formation. Mol. Biol. Cell 2014, 25, 2750-2760. [CrossRef]

49. Yukawa, M.; Yamada, Y.; Yamauchi, T.; Toda, T. Two spatially distinct kinesin-14 proteins, Pkl1 and Klp2, generate collaborative inward forces against kinesin-5 Cut7 in S. pombe. J. Cell Sci. 2018, 131, 1-11. [CrossRef]

50. Peset, I.; Vernos, I. The TACC proteins: TACC-ling microtubule dynamics and centrosome function. Trends Cell Biol. 2008, 18, 379-388. [CrossRef]

51. Li, W.; Miki, T.; Watanabe, T.; Kakeno, M.; Sugiyama, I.; Kaibuchi, K.; Goshima, G. EB1 promotes microtubule dynamics by recruiting Sentin in Drosophila cells. J. Cell Biol. 2011, 193, 973-983. [CrossRef] [PubMed]

52. van der Vaart, B.; Manatschal, C.; Grigoriev, I.; Olieric, V.; Gouveia, S.M.; Bjelic, S.; Demmers, J.; Vorobjev, I.; Hoogenraad, C.C.; Steinmetz, M.O.; et al. SLAIN2 links microtubule plus end-tracking proteins and controls microtubule growth in interphase. J. Cell Biol. 2011, 193, 1083-1099. [CrossRef]

53. Zanic, M.; Widlund, P.O.; Hyman, A.A.; Howard, J. Synergy between XMAP215 and EB1 increases microtubule growth rates to physiological levels. Nat. Cell Biol. 2013, 15, 688-693. [CrossRef] [PubMed]

54. Gunzelmann, J.; Ruthnick, D.; Lin, T.C.; Zhang, W.; Neuner, A.; Jakle, U.; Schiebel, E. The microtubule polymerase Stu2 promotes oligomerization of the $\gamma$-TuSC for cytoplasmic microtubule nucleation. eLife 2018, 7, e39932. [CrossRef]

55. Woodruff, J.B.; Ferreira Gomes, B.; Widlund, P.O.; Mahamid, J.; Honigmann, A.; Hyman, A.A. The centrosome is a selective condensate that nucleates microtubules by concentrating tubulin. Cell 2017, 169, 1066-1077 e10. [CrossRef]

56. George, A.A.; Walworth, N.C. Escape from mitotic arrest: An unexpected connection between microtubule dynamics and epigenetic regulation of centromeric chromatin in Schizosaccharomyces pombe. Genetics 2015, 201, 1467-1478. [CrossRef]

57. Moreno, S.; Klar, A.; Nurse, P. Molecular genetic analysis of fission yeast Schizosaccharomyces pombe. Methods Enzymol. 1991, 194, 795-823. 
58. Sato, M.; Dhut, S.; Toda, T. New drug-resistant cassettes for gene disruption and epitope tagging in Schizosaccharomyces pombe. Yeast 2005, 22, 583-591. [CrossRef]

59. Bahler, J.; Wu, J.Q.; Longtine, M.S.; Shah, N.G.; McKenzie, A., 3rd; Steever, A.B.; Wach, A.; Philippsen, P.; Pringle, J.R. Heterologous modules for efficient and versatile PCR-based gene targeting in Schizosaccharomyces pombe. Yeast 1998, 14, 943-951. [CrossRef]

(C) 2019 by the authors. Licensee MDPI, Basel, Switzerland. This article is an open access article distributed under the terms and conditions of the Creative Commons Attribution (CC BY) license (http://creativecommons.org/licenses/by/4.0/). 